\title{
Complementary Feeding Practices of Nepali Mothers for 6 Months to 24 Months Children
}

\author{
Ram Hari Chapagain' \\ 'Department of Pediatrics, Mahakali Zonal Hospital, Mahendranagar, Nepal.
}

Introduction: Lack of knowledge and proper feeding practices contribute to higher childhood morbidity and mortality. The aim of the study wasto evaluate the mother's knowledge and practices in terms of quantity, quality and timing of complementary feeding in infant and young child.

Methods: A hospital based cross-sectional study was conducted between June, 2010 to October, 2011, at Kanti Children's Hospital, Nepal, involving 1100 mothers of children from 6 to 24 months of age who attended outpatient department of this hospital, applying systematic sampling technique using semi-structured questionnaire.

Results: Eighty-seven percent of mothers had knowledge about the duration of exclusive breast feeding but only $33.0 \%$ practiced it and $21.0 \%$ breast fed their children up to 3 months. Eighty-seven percent of mothers knew when to start complementary feeding and $53.27 \%$ of mothers used the marketed weaning food. lito alone was offered by $28.27 \%$ as complementary food. Though $36.6 \%$ had proper knowledge of frequency of complementary feeding, only $33.27 \%$ were actually practicing it and $9.9 \%$ were offering more frequent thanrecommended. About half of the mothers fed their child with the food of appropriate consistency and $66.0 \%$ fed with the appropriate amount. But only $15.82 \%$ mothers fed their children with ideal frequency, sufficient amount and ideal quality.

Conclusions: There was a knowledge and practice gap of duration of exclusive breast feeding and initiation and continuation of ideal complementary feeding. Rate of exclusive breast feeding was on declining trend.

Keywords: complementary feeding; exclusive breast feeding; infant and young child feeding; ideal feeding.

\section{INTRODUCTION}

An appropriate diet is critical in growth and development of children especially in the first two years of life. World Health Organization (WHO) recommends exclusive breast-feeding (BF) for the first six month of age. Addition of complementary feeds at six months with continued BF till two years which if followed appropriately can decrease infant mortality by 19 percent and prevent malnutrition especially in developing countries like ours. ${ }^{1-3}$ Nepal has been trying its best to achieve the
Millennium Development Goals (MDG) to reduce the childhood mortality by two thirds by 2015 though it has a long way to go. ${ }^{4}$ Poor nutrition increases the risk of illness, and is responsible, directly or indirectly, for one third of the estimated 9.5 million deaths that occurred

Correspondence: Dr. Ram Hari Chapagain, Department of Pediatrics, Mahakali Zonal Hospital, Mahendranagr, Nepal. Email: chapagainrh2008@gmail.com, Phone: +977-9841409080. 
in 2006 in children less than five years of age. ${ }^{5-7}$

Complementary feeds bridge the energy, vitamin A and iron gaps which arise in breastfed infants at 6 month of age..$^{8,9}$ Early introduction of complementary feeds is associated with increased morbidity due to diarrheal diseases and development of malnutrition in areas with poor food or water hygiene. ${ }^{10,11}$ On the other hand, too long delay in introducing appropriate complementary foods may lead to nutritional deficiencies of iron, zinc, calcium and sometimes vitamin $\mathrm{A}$ and riboflavin. ${ }^{12}$ Cultural practices; beliefs and knowledge of parents regarding appropriate feeding practices influence CF. ${ }^{2}$ There is scarcity of studies on knowledge and practices about CF. ${ }^{7,13-15}$ Knowledge of these factors will be helpful in planning interventions to improve feeding practices. ${ }^{16,17}$

\section{METHODS}

A hospital based cross-sectional study was conducted between June, 2010 to October, 2011, at Kanti Children's Hospital, Nepal, involving mothers of children from 6 to 24 months of age who attended outpatient department of this hospital, applying systematic sampling technique excluding mothers of child less than 6 months and more than 24 months and using semistructured questionnaire. During the study period, 1100 mothers were interviewed. Children seeking emergency care, those with known anomalies and the ones who failed to provide consent were excluded. Statistical analysis was done with Statistical program for social studies (SPSS) version19. Percentage, proportions and contingency tables were used for description of the data.

\section{RESULTS}

Out of the total 1100 respondents, around two third $(61.60 \%)$ were below 26 years. The mean age was 24.9 years with the standard deviation of 4.107 with range of 15 to 44 years. The range was 6 months to 24 months with the mean of 12.84 months with the SD of 5.52 . Nuclear family system was more common than joint family $(64.3 \%$ vs $35.7 \%)$ and most of the respondents were from city $(55.3 \%)$ followed by town $(24.1 \%)$ and rest were from rural areas (Table 1$)$.

\begin{tabular}{|l|l|}
\hline $\begin{array}{l}\text { Table1. Socio-demographic Characteristics of } \\
\text { respondents. }\end{array}$ \\
\hline Characteristics $\quad$ Frequency \\
(n=1100)
\end{tabular}

\begin{tabular}{|c|c|c|}
\hline $6-8$ & 284 & 25.8 \\
\hline $9-11$ & 257 & 23.4 \\
\hline $\begin{array}{l}12 \text { or above } \\
\text { Mean age + SD }\end{array}$ & $\begin{array}{l}559 \\
12.84+5.529 \mathrm{mo}\end{array}$ & 50.8 \\
\hline \multicolumn{3}{|l|}{ Sex } \\
\hline Male & 699 & 63.5 \\
\hline Female & 401 & 36.5 \\
\hline \multicolumn{3}{|l|}{ Mother's age } \\
\hline$<20$ & 128 & 11.65 \\
\hline $21-30$ & 884 & 80.36 \\
\hline $31-40$ & 88 & 7.99 \\
\hline \multicolumn{3}{|l|}{ Type of family } \\
\hline Nuclear & 707 & 64.3 \\
\hline Joint & 393 & 35.7 \\
\hline
\end{tabular}

\begin{tabular}{|lll|}
\hline Education of mother & & \\
\hline No education & 208 & 18.9 \\
primary education & 166 & 15.1 \\
some secondary & 342 & 31.1 \\
SLC Intermediate & 279 & 25.4 \\
Bachelor and above & 105 & 9.5 \\
Education of father & & \\
No education & 99 & 9.0 \\
primary education & 147 & 13.4 \\
some secondary & 335 & 30.5 \\
SLC Intermediate & 359 & 32.6 \\
Bachelor and above & 160 & 14.5 \\
\hline
\end{tabular}

\begin{tabular}{|lll|}
\hline Profession & & \\
\hline House wife & 782 & 71.1 \\
HW with Agriculture & 153 & 13.9 \\
Business & 70 & 6.4 \\
Service & 61 & 5.5 \\
Skilled work & 24 & 2.2 \\
Labour & 10 & 0.9 \\
Profession of father & & \\
Unemployed & 8 & 0.7 \\
Agriculture & 99 & 9.0 \\
Business & 204 & 18.5 \\
Skilled work & 337 & 30.6 \\
Service & 340 & 30.9 \\
Labour & 36 & 3.3 \\
Foreign employee & 76 & 6.9 \\
\hline
\end{tabular}

Most of the mothers $(87.3 \%)$ had knowledge about the duration of exclusive breast-feeding and the time to start complementary feeding. Only $12.7 \%$ mothers had no ideas about when to start complementary feeding as 
well as the duration of exclusive breast-feeding.It was observed that 6 out of 10 mothers did not know about the frequency of feeding to their child as per age of their child. Only $36.6 \%$ mother knew about the frequency of feeding required to their child (Table 2).

\begin{tabular}{|l|l|}
\hline $\begin{array}{l}\text { Table 2. Mother's knowledge related characteristics } \\
\text { of infant and young child feeding. }\end{array}$ \\
\hline Characteristics & $\begin{array}{l}\text { Frequency } \\
(\mathrm{n}=1100)\end{array}$ \\
\hline
\end{tabular}

\begin{tabular}{|lcc|}
\hline \multicolumn{3}{|l|}{ Knowledge to start complementary feeding } \\
\hline Yes & 960 & 87.3 \\
No & 140 & 12.7 \\
\hline
\end{tabular}

\begin{tabular}{|lcc|}
\hline \multicolumn{2}{|l|}{ Knowledge about duration of exclusive breast } \\
feeding
\end{tabular}

\begin{tabular}{|lcc|}
\hline \multicolumn{2}{|l|}{ Knowledge of frequency of complementary feeding } \\
\hline Yes & 403 & 36.36 \\
No & 679 & 63.4 \\
\hline
\end{tabular}

One fifth (16.69\%) had practice of exclusive breast feeding less than 3 months and 1 in every 14 mother breast fed her child exclusively for less than one month. However, it was observed that $8.9 \%$ mothers had practice of exclusive breast feeding more than 6 months. The commonest reason for prolonged exclusive breast feeding was their perception of breast milk being enough for their children and few $(1.81 \%)$ did not know why they were practicing so.

Almost $90.0 \%$ mothers offered their colostrum to their child as first feed and $11.0 \%$ mothers used infant formulas as first feed to their child. Whereas vey negligible number had offered the cow/buffalo milk and water as first feed to their child (Table 3 ). More than half $(56.81 \%)$ of mothers fed their child less than prescribed frequencies per day. Whereas one among 10 mothers fed more frequent than required and only one third mothers fed their children as per recommendation. Likewise half of the mothers fed their child either thin or thick food and 4 among 5 mothers feed their child appropriate amount. In computing the ideal feeding only $15.82 \%$ of mothers fed their child ideally means normal amount with appropriate consistency and appropriate frequency in a day (Table 4).

\begin{tabular}{|lcl|}
\hline \multicolumn{3}{|l|}{$\begin{array}{l}\text { Table 3. Practice related characteristics of Infant } \\
\text { and young child feeding. }\end{array}$} \\
\hline \multicolumn{3}{|c|}{$\begin{array}{l}\text { Frequency } \\
\text { (N=1100) } \%\end{array}$} \\
Characteriests & \multicolumn{3}{|c|}{ Duration of exclusive breast feeding (n=1100) } \\
$<1$ month & 67 & 6.19 \\
1 month & 50 & 4.54 \\
2 months & 66 & 6.00 \\
3 months & 156 & 14.18 \\
4 months & 102 & 9.18 \\
5 months & 198 & 18.00 \\
6 months & 364 & 33.19 \\
$>6$ months & 97 & 8.90 \\
First feed offered to child & (n=1100) \\
Colostrum & 961 & 87.36 \\
Infant formulas & 123 & 11.18 \\
Cows/Buffalos & 13 & 1.18 \\
milk & 3 & 0.28 \\
Water & & \\
\hline
\end{tabular}

\begin{tabular}{|lll|}
\hline $\begin{array}{l}\text { Complementary food } \\
\text { offered }(\mathrm{n}=1100)\end{array}$ & \\
\hline Lito & 311 & 28.27 \\
Cerelacs & 74 & 6.72 \\
Dal bhat & 83 & 7.54 \\
Lito, cerelac & 210 & 19.09 \\
lito, dal ,bhat & 280 & 25.46 \\
Cerelac, dal bhat & 51 & 4.63 \\
All (lito,cerelac, dal bhat) & 91 & 8.27 \\
\hline
\end{tabular}

\begin{tabular}{|c|c|c|}
\hline \multicolumn{2}{|c|}{ Reason for delayed complementary feeding } & \multirow{2}{*}{$\begin{array}{c}\mathbf{n}=\mathbf{9 7} \\
0.18\end{array}$} \\
\hline Vomits everything & 2 & \\
\hline Milk is enough & 71 & 6.45 \\
\hline Elder told to do so & 3 & 0.27 \\
\hline $\begin{array}{l}\text { Child did not accept other } \\
\text { foods }\end{array}$ & 1 & \\
\hline Don't know & 20 & 1.81 \\
\hline \multicolumn{3}{|c|}{ Preparation of complementary feeding $(n=1100)$} \\
\hline Cereals & 87 & 7.91 \\
\hline Cereals and pulses & 866 & 78.73 \\
\hline Cereals pulses and ghee & 146 & 13.27 \\
\hline $\begin{array}{l}\text { Cereals pulses ghee and green } \\
\text { vegetables }\end{array}$ & 1 & 0.09 \\
\hline \multicolumn{3}{|c|}{ Use of marketed complementary feeding } \\
\hline Yes & & 53.27 \\
\hline No & & 46.72 \\
\hline
\end{tabular}




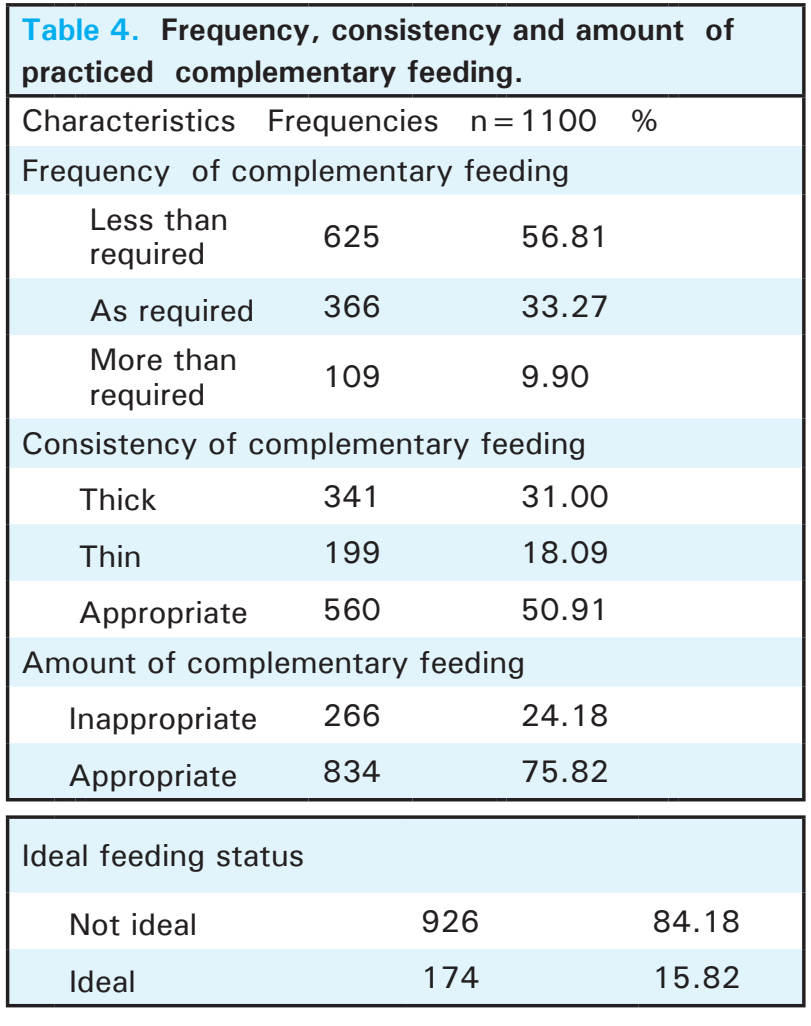

\section{DISCUSSION}

Infant and young child feeding (IYCF) practices include early initiation of breast feeding within one hour of life, timely introduction of solid/semi solid foods from the age of six months increasing in amount and frequency over time along with breast feeding as demanded by child. The National demographic health survey 2011 concluded that complementary foods are not introduced in a timely fashion for all children in Nepal. Seventy percent of infants have been given complementary foods by age 6-9 months. ${ }^{18}$

It is encouraging to note that the percentage of mothers who knew the duration of exclusive breast feeding was $87.3 \%$ but only $33.0 \%$ were found to be actually practicing it. It shows the gap between knowledge and practice is high despite the fact that Nepal's Breast Milk Substitute Act 1992 (2049) promotes and protects breastfeeding and regulates the unauthorized or unsolicited sale and distribution of breast milk substitutes (Ministry of Health and Population, 2004b). One of the reasons for such big gap observed in our study could be due to cultural practice of initiating of complementary feeding. Among many cultures in Nepal the first time solid food given is solemnized with a formal ceremony called Pasneor the rice feeding ceremony. ${ }^{19}$ Other reason could be busy mothers such as workers and students. Our result is comparable with global situation. Worldwide, it is estimated that only
$34.8 \%$ of infants are exclusively breastfed for the first 6 months of life and majority of them receive some other foods or fluids in the early months of life. ${ }^{9}$ But this result is less than the results of NDHS 2006 and $2011.7,18,19$

Most mothers (87.3\%) knew when to start complementary feeding but only $36.6 \%$ mothers knew about the appropriate frequency. The findings are similar to NDHS reports. ${ }^{18}$

A few mothers (6.2\%) give exclusive breast feeding only for less than a month and $1 / 5^{\text {th }}$ of the mothers $(21.0 \%)$ less than three months which is very early than recommended by WHO. This early initiation of giving other foods might be due to the fact that mothers are engaged in other jobs or the belief of equally effectiveness of other formula feeds to the child. Similar findings were also observed by other studies conducted in Nepal and India. ${ }^{20-23}$

This study found that $87.3 \%$ of mothers used colostrum as first feed and the remaining percentage of mothers used infant formulas, cow/buffalos milk and water as first feed. Similar findings were reported by NDHS survey 2011 and the other studies done in urban as well as rural communities in Nepal. ${ }^{20,21}$ Our finding of colostrum use as a first feed is much higher than reported bystudies in Nigeria, a underdeveloped country like ours. ${ }^{24}$ Another Nigerian studyin semi urban setting found exclusive breast-feeding rate to be low $(33.0 \%){ }^{25}$

Though, most of the mothers begin to feed their infants with colostrum, the percentage of mothers giving exclusive breast feeding goes decreasing with the age of child. This study found almost all $(94.82 \%)$ mothers fed their infants with only breast milk till the age of one month which came down to $33.19 \%$ at the age of 6 months. This evidence shows that the trend of mix feeding is increasing. This phenomenon is true for the developed world as well. A Switzerland study showed that $94 \%$ of the infants were breastfed in the first months but by the age of 5 months, as much as half of the infants received formula milk. ${ }^{25}$

It was found in this study that around $9.0 \%$ mothers practiced exclusive breast feeding more than 6 months and the most common reasons given by them were enough milk production, acceptability of the mother's milk by babies, suggestion of the elders in the family and vomiting of other feeds by the baby. Another study conducted in another city of Nepal (Pokhara) reported that even higher percentage of mothers continued exclusive breast-feeding beyond six months. ${ }^{22}$ The differences between the findings of those two studies could 
be due to the difference in study population. The study done in Pokhara was community based however the reasons given for the continuing exclusive breast feeding beyond six months of age were the same as observed in our study. ${ }^{7,22}$ Reasons for not breast feeding exclusively or stopping it early have not been identified in this study and are topics for further research.

It seems that the trend of using marketed weaning food is increasing. Study found that $53.27 \%$ of mothers used the marketed weaning foods. Similar phenomenon was observed by Aggarwal et.al in India. They reported that $19 \%$ of mothers used marketed weaning food. ${ }^{7}$

Though $87.3 \%$ of mothers had knowledge about the time of initiation of complementary food, $31.0 \%$ of mothers started complementary feed within 3 months of age and $8.9 \%$ of mothers did not start complementary feeding even at 6 months of age. Both practices are not onlyundesirablebut also harmful to our children but unfortunately, are being still practised in the developing world. ${ }^{7,10,13}$ It was found in our study that the reasons for late starting of complementary feeding were: milk is enough, elders told to do so, vomits everything and don't know why they did it but they did it. Similar type of finding was observed in another study done in India. ${ }^{7}$ This study found that $33.27 \%$ of mothers were giving the feeds as per WHO guidelines and $9.90 \%$ were giving more often than prescribed frequency. Combining together $43.17 \%$ of mothers were giving feed at adequate frequency. When assessing the knowledge about the frequency of complementary feeding, it was found that more than $1 / 3^{\text {rd }}(36.6 \%)$ had proper knowledge of frequency of complementary feeding. This shows that almost all the mothers having knowledge are practicing the complementary feeding. However, this finding is much less as compared to the reports by NDHS 2006. ${ }^{19}$ This might be because of the different location of the study. Similar finding was observed in India by Agrawal et.al. ${ }^{7}$ We have to be cautious about the observation on more frequent feeding than recommendation as it may be the cause of obesity in the future even in developing countries.

This study found that half of the mothers fed their child either thick or thin feeds and only $50.91 \%$ mother fed their children appropriate complementary feeding by consistency. Consistency of CF is not mentioned in our NDHS 2006, however, the study done in India found the $25.5 \%$ to $30.0 \%$ mothers knew and practiced the recommended complementary feeding by consistency which is lower than our finding. ${ }^{7,14,18}$ This variation might be due to the difference in study population and their demographic characteristics. It would have been more useful and informative if such characteristics were studied in our country too.

It is interesting to note that 3 among 4 mothers in our study had fed their baby the appropriate amount of feeding. This reveals that mothers in our part of world are more concerned about the amount of feed offered to their child. Though the amount of feed is sufficient, they may be still deficient in calories and nutritional values. These feeds are either thick or thin and don't have all the ingredients required to be the ideal complementary feeding. This might be one of the possible factors for high prevalence of under-nutrition, wasting and stunting despite the use of correct amount of feeding.

Ideal CF comprises of adequate frequency, sufficient quality, and quantity of the feed as per WHO recommendation. However, only $15.82 \%$ mothers were found be practicing ideal feeding in this study. Similar observation was observed in the study done in India. ${ }^{7,13}$ Most of the studies have evaluated complementary feeding only in terms of frequency without considering

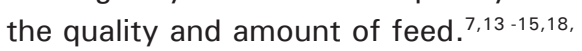

\section{CONCLUSION}

The ideal feeding was practiced only in a minority of children. There was a big gap between the knowledge of mothers about duration of exclusive breast feeding and their practices. However, the practices of giving colostrums was interestingly very high.

Some of the others use lito as a weaning food but the proper method of its preparation was known to a few mothers. Amount of complementary feeding given to children was enough in the majority of the children but it's consistency and frequency were found to be not appropriate as per recommendation in more than half of the children.

\section{REFERENCES}

1. World Health Organization (WHO). The optimal duration of exclusive breast-feeding: report of an expert consultation (WHO/FCH/CAH/01.24). Geneva: March 2001.
2. World Health Organization (WHO). Global forum for child health research: a foundation for improving child health. Switzerland,Geneva,WHO, 2002[Online]. 2011. [Cited May 2011]. Accessible from:URL:http://www.who.int/child_ adolescent_health/new_publications. 
3. Gareth J, Stekette RW, Black RE, Bhutta ZA, Morris SS. How many child deaths can we prevent this year? Lancet. 2003;362:65-71.

4. United Nations (UN). The Millennium Development Goals Report: United Nation; 2010.

5. World Health Organization. The global burden of disease: 2004 update. WHO: Geneva; 2008.

6. Black RE. Maternal and child under nutrition: global and regional exposures and health consequences. Lancet. 2008;371:243-60.

7. Aggrawal A, Verma S, Feridi MA, Chand D. Complementary Feeding-Reasons for Inappropritateness inTiming,Quality and consistency. Indian J Pediatr. 2008;75:49-56.

8. Dratva J, Merten S, Ackermann-LiebrichU.The timing of complementary feeding of infants in Switzerland with the Swiss and the WHO guidelines.Actapaediatrica. 2006;95:818-25.

9. WHO.The optimal duration of exclusive breast feeding.A systematic review. Document WHO/NHD/01.08 Geneva: WHO;2001.

10. Gibson RS, Ferguson EL, Lehrfeld J. Complementary foods for infant feeding in developing countries: their nutrient adequacy and improvement. Eur J ClinNutr. 1998;52:764-70.

11. Simondon KB, Simondon F. Age at introduction of complementary food and physical growth from 2 to 9 months in rural Senegal. Eur J ClinNutr. 1997;51:703-7.

12. Barbera J. Infections for the infants. InStoll,Kliegman,Behrman(eds). Nelson Textbook of Pediatrics.18th ed. Philadelphia, Saunders Elsvier 2009, P 794-9.

13. Vaahtera M, Kulmala T, Hietanen A, Mdekha M, Cullinan $\mathrm{T}$, Salin ML et al. Breast feeding and complementary feeding practices in rural Malawi. ActaPaediatr. 2001;90:328-32.

14. Sethi V, Kashyap S,Sethi V. Effects of nutritional education of mothers on infant feeding practices. Indian J Pediatr. 2003;70:463-6.
15. Bhandari N, Mazumdar S, Bahl R, Mortines J, Black RE,Bhan MK. An educational intervention to promote appropriate complementary feeding practices and physical growth in infants and young children in rural Haryana. J Nutr. 2004;134:2342-8.

16. Alive and Thrive Initiative. Alive and Thrive 1825 connecticut Ave. Washigton D C; 2009.

17. Singh B. Knowledge,attitude and practice of breast feeding - A Case Study. European Journal of Scientific Research. 2010;40(3):404-22.

18. Population Division, MOH,Government of Nepal.Nepal demographic Health Survey, Kathmandu 2011;150-81.

19. Population Division, MOH, Government of Nepal.Nepal demographic Health Survey, Kathmandu 2006;180-81.

20. Basnet S, Gauchan E, Malla K, Malla T, Koirala DP, Rao K Set al. Infant Feeding Practice in KaskiDistrict, Pokhara. Nepal Pediatric Soc. 2012;32(1):23-7.

21. Pandey S, Tiwari K, Senarath U, Agho KE, Bibley MJ. Determinants of infant and young child feeding practices of Nepal: Secondary data analysis of DHS 2006. Food and Nutrition Bulletin. 2010;31(2):334-51.

22. Subba SH,Chandrashekhar TS,Binu VS, Joshi HS, Rana MS, Dixit SB. Infant feeding practices of mothers in an Urban areas in Nepal. Kathmandu University Medical Journal. 2007;5(1):42-7.

23. Igbedioh S, dache OE, Akaka HJ. Comparative Infant weaning practices of some Idoma women in Makurdi, Nigeria.Nutr Health. 1995;10(3):239-53.

24. Ogunlesi TA. Maternal and socioeconomic factors Influencing the initiation and Exclusivity of Breast feeding in a Nigerian Semi Urban Setting .Maternal and Child Health J. 2010;14:459-65.

25. Hetzner NM, Razza RA, Malone LM, Brooks-Gunn J. Associations among feeding behaviors during infancy and child illness at two years. Matern Child Health J. 2009;13(6):795-805. 